\title{
Total and Antigen-Specific Ige Levels in Umbilical Cord Blood
}

\author{
A. J. Sybilski1, 2, A. Doboszynska³, B. Samolinski ${ }^{1}$ \\ ${ }^{1}$ Department of the Prevention of Environmental Hazards and Allergology, Warsaw Medical University, Warsaw, Poland; \\ ${ }^{2}$ Department of Pediatric and Neonatology, Central Clinical Hospital of Ministry of Internal Affairs, Warsaw, Poland; \\ ${ }^{3}$ Department of Clinical Nursing, Warsaw Medical University, Warsaw, Poland
}

\begin{abstract}
The present study was conducted to learn whether the perinatal and environmental factors could influence the total and antigen-specific $\operatorname{IgE}$ levels in umbilical cord blood. Retrospective data were obtained from 173 mother-infant pairs. Total and specific (for children's food, wheat/grass and house dust mite-HDM) cord blood IgE levels were determined using the immunoassay test. The total cord blood IgE was between 0.0-23.08 IU/ml (mean $0.55 \pm 2.07 \mathrm{IU} / \mathrm{ml}$; median $0.16 \mathrm{IU} / \mathrm{ml}$ ). Total IgE levels were significantly higher in boys compared with girls $(\mathrm{OR}=2.2 ; \mathrm{P}=0.007)$, and in newborns with complicated pregnancy $(\mathrm{OR}=2.7$; $\mathrm{P}=0.003)$. A greater number of siblings correlated with increases in the total cord blood $\operatorname{IgE}(\mathrm{P}<0.02)$. We detected specific IgE in 34 newborns (40 positive tests). A long-standing contact with a cat during pregnancy decreased the specific IgE level for wheat/grass $(\mathrm{OR}=3.2 ; \mathrm{P}<0.07)$ and for children's food $(\mathrm{OR}=5.0$; $\mathrm{P}<0.04)$, and the contact with a dog decreased the specific-IgE for wheat/grass $(\mathrm{OR}=0.3 ; \mathrm{P}<0.05)$. Exposure to tobacco smoke correlated with the positive specific $\operatorname{IgE}$ toward house dust mite $(\mathrm{OR}=4.7$; $\mathrm{P}=0.005)$.
\end{abstract}

Key words: umbilical cord blood, IgE, antigen-specific $\mathrm{IgE}$, perinatal factors

\section{INTRODUCTION}

Genetic nature of allergy and complex mechanisms governing the development of atopic phenotype already in fetal life have since long been recognized. The process of hypersensitization begins synchronously with the initiation of fetal production of immunoglobulin $\mathrm{E}$ in the 11th gestational week [1, 2]. The IgE level in umbilical cord blood may have a significant influence on the future development of atopic diseases. Therefore, factors influencing $\operatorname{IgE}$ level in umbilical blood plasma may modify the course of allergy and the development of atopic symptoms.

The aim of the present study was to evaluate the influence of genetically determined susceptibility and of selected environmental factors on the total $\mathrm{IgE}$ level and on the presence of selected antigen-specific IgE in umbilical cord blood plasma.

\section{MATERIAl AND Methods}

The study was approved by a local Ethics Committee. This is a retrospective study in which the enrollment of patients depended on obtaining informed parental consent. Overall, the analysis included 173 newborns (86 boys, 87 girls). The exclusion criteria were: low birth weight (less than $2500 \mathrm{~g}$ ), severe co-morbidity, e.g., congenital defects, perinatal trauma, intracranial hemorrhage, other life-threatening conditions in the perinatal period. A retrospective survey of pregnancy and labor and family history was performed using a self-developed questionnaire. The questionnaire was based on interviews with newborns' mothers or both parents. We collected data on pregnancy complications (especially infections), type of delivery, gender, birth weight, gestational age, Apgar score, mother and father lifestyle and habits, and environmental factors. After collecting the family history, notably about atopic diseases, we stratified the estimated risk of developing atopy into 4 groups: no risk - no atopy diseases in the child's family; mild risk -atopy disease in the extended family; moderate risk - father and/or siblings with atopy disease; severe risk - mother and/or father and siblings with atopy diseases. The presence of atopy was considered a basis for the physicians' diagnosis of the following atopic diseases: bronchial asthma, atopic dermatitis, hay fever, urticaria, atopic conjunctivitis, food allergy.

Umbilical cord blood $(4 \mathrm{ml})$ was obtained at the time of delivery. Total serum IgE levels were determined by the electrochemiluminescense immunoassay ECLIA - sandwich principle in an Elecsys 2010 analyzer (Roche Diagnostics, Mannheim, Germany) with a detection level of $0.1 \mathrm{IU} / \mathrm{ml}$. Specific umbilical cord blood $\mathrm{IgE}$ was assessed for the following allergen kits: children's food: egg, milk, wheat meal, and peanuts; soya; grass and grain pollen (the most common in Poland); house dust mite (HDM): D. pteronyssinus and D. farinae. Specific cord blood $\operatorname{IgE}$ was measured by the enzyme-linked immunosorbent assay ELISA in an Allergopharma analyzer (Allergopharma, Reinbek, Germany), with the detection level of $0.35 \mathrm{IU} / \mathrm{ml}$.

Data were expressed as means $\pm \mathrm{SD}$ and were analyzed in relation to the median and mean levels of cord blood IgE. Concerning the former, children were 
subdivided into two groups, below and above the median level of $\operatorname{IgE}$; concerning the latter, children were divided into 3 groups, depending on their total mean $\mathrm{IgE}$. The following environmental factors which might affect the total $\mathrm{IgE}$ level were analyzed: family history of allergy, pregnancy and labor-associated events, environmental factors, and parental behavior in the prenatal period. Associations between clinical and epidemiological data collected by a questionnaire and the allergy were analyzed by a Chi-square test with Yates's correction and Fisher's test, according to a given contingency table. Differences in immunoglobulin levels between the case and control groups were tested by a Whitney-Mann U test. Moreover, Spearman's rank correlation coefficient was used to test associations between the studied factors.

\section{RESULTS}

\section{Total IgE in Umbilical Blood Plasma}

Fig. 1A shows the number of children with the $\operatorname{IgE}$ below and above the median level born from normal and pathologically complicated pregnancies. In normal pregnancies, there were about twice more children with the $\operatorname{IgE}$ below than above the median level. This ratio was reversed toward the preeminence of the above median level in pathological pregnancies. On the other hand, the numbers of children with the $\operatorname{IgE}$ below and above its median level were about equal when there was no atopic rhinitis in history, whereas there were twice as many children with the $\operatorname{IgE}$ above its median level in case of history of atopy (Fig. 1B).

The total $\mathrm{IgE}$ level in umbilical blood plasma was in a range from 0.0 to $23.08 \mathrm{IU} / \mathrm{ml}$ (mean $0.55 \pm 2.07$ $\mathrm{IU} / \mathrm{ml}$; median $0.16 \mathrm{IU} / \mathrm{ml})$. The neonates were divided into 3 groups based on the cord blood IgE level: the first group with the $\operatorname{IgE}<0.1 \mathrm{IU} / \mathrm{ml}$ consisted of 65 infants $(37.5 \%)$, the second with the IgE $0.1-0.5$ $\mathrm{IU} / \mathrm{ml}$ consisted of 63 infants $(36.5 \%)$, and the third with the $\operatorname{IgE}>0.5 \mathrm{IU} / \mathrm{ml}$ consisted of 45 infants $(26.0 \%)$. In the first group there were 24 boys and 41 girls, in the second 36 and 27, and in the third 26 and 19 , respectively.

Overall, the total cord blood IgE levels were significantly higher in boys compared with girls (means 0.82 \pm 2.69 vs. $0.39 \pm 1.14 ; \mathrm{OR}=2.2 ; \mathrm{P}=0.007$ ), in newborns with complicated as opposed to normal pregnancy (means $0.75 \pm 2.37$ vs. $0.17 \pm 0.26$; $\mathrm{OR}=2.7$; $\mathrm{P}=0.003$ ) and in newborns with family history of atopic rhinitis as opposed to the lack of such history (means $1.45 \pm$
4.84 vs. $0.48 \pm 1.26 ; \mathrm{OR}=2.4 ; \mathrm{P}=0.03)$. Family size (the number of siblings) correlated with decreases of cord blood IgE levels $(\mathrm{P}<0.02)$. For the remaining variables (allergic diseases in the mother, father, or siblings), no statistically significant differences were noted. No correlations were observed between infant's exposure to allergy and the total $\operatorname{IgE}$ level.

\section{Antigen-SPeCific IgE in Umbilical Blood Plasma}

Overall, 519 assays for antigen-specific $\operatorname{IgE}$ were performed (3 x 173 children). We detected specific $\mathrm{IgE}$ in 34 newborns - 19.7\% (6.6\% positive tests). Of the 40 positive tests, 20 were to grass and grain pollen, 11 to HDM, 9 to food. Fifteen children had specific IgE to grass, 8 to HDM, 5 to food, 2 to grass and HDM, 3 to grass and food, 1 to HDM and food. No correlations were noted between familial history of allergy and the presence of specific immunoglobulins. No statistically significant correlation was seen between antigen-specific IgE in umbilical blood plasma and pregnancy- or labor-associated factors. The analyzed environmental factors included: place of residence (urban or rural), living conditions and crowding (number of people per room), the presence and kind of domestic animals during pregnancy, and environmental pollution. Contact with cat's allergens caused a higher prevalence of the specific $\operatorname{IgE}$ for grass and grain pollen $(\mathrm{OR}=3.24$; $\mathrm{P}<0.07)$ and children's food $(\mathrm{OR}=4.98 ; \mathrm{P}<0.04)$. Specific IgE for grass and grain pollen were significantly lower in case of household contact with a dog during pregnancy $(\mathrm{OR}=0.28 ; \mathrm{P}<0.05)$. No significant correlations were found between the other environmental factors and the presence of $\mathrm{IgE}$ in umbilical blood plasma.

Analysis of parental tobacco smoking habits during pregnancy revealed a significant association between the level of antigen-specific IgE against domestic dust mites and maternal tobacco smoking. These antibodies were detected significantly more often in newborns of smoking mothers and this correlated with the umber of cigarettes smoked per day $(\mathrm{OR}=4.7 ; \mathrm{P}=0.005)$. A similar correlation $(\mathrm{P}=0.04)$ was noted when analyzing smoking habits of both parents combined.

\section{Discussion}

Thinking about factors influencing the levels of total and antigen-specific $\mathrm{IgE}$ in umbilical blood plasma, investigations focused on genetic predispositions, environmental factors and parental behavior. Authors em-

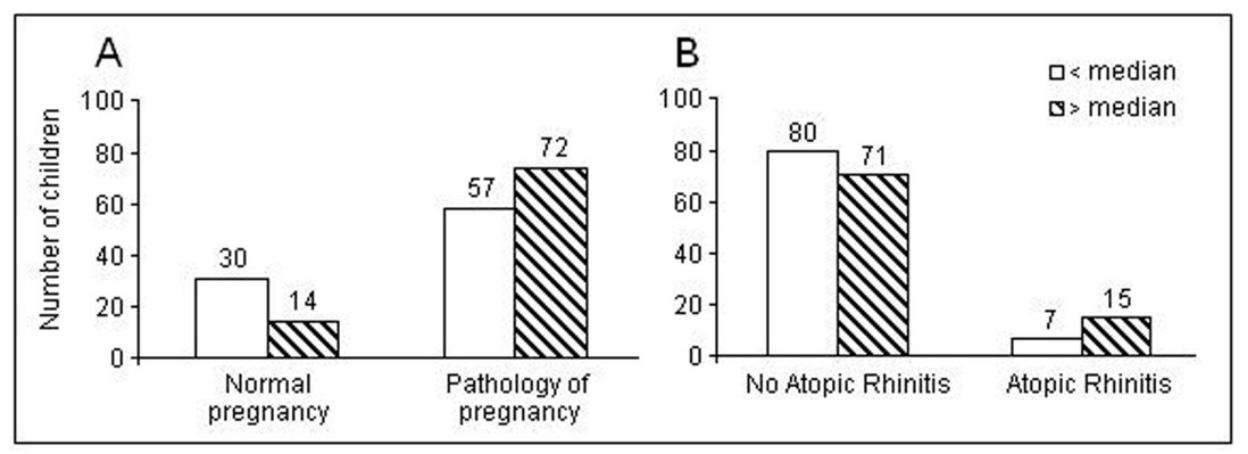

Fig. 1. Umbilical cord blood $\mathrm{IgE}$ concentration below and above the median level in relation to the normal or pathological pregnancy course (Panel A) and to the presence of atopic rhinitis in history. 
phasize the influence of all these factors combined, although it is a matter of debate which one is the most important $[1,2]$.

A frequently studied issue is the influence of atopic diseases in the family on the level of total $\operatorname{IgE}$ in umbilical blood. Several reports suggest that atopy in parents, siblings, and 1 st degree relatives is a presage of a significant increase in the $\mathrm{IgE}$ level, which could be followed by increased incidence of atopic diseases in infancy $[3,4,5]$. Most authors point to the presence of atopic diseases, particularly in the mother, as a key factor contributing to elevated levels of $\operatorname{IgE}$ in umbilical blood. It has also been noticed that the presence of allergy in the father or in another relative is less important $[6,7,8]$. The results obtained in the present study partially support that thesis. The presence of atopic rhinitis in the child's family presages a significant increase in $\mathrm{IgE}$ level.

Since the discovery of $\mathrm{IgE}$ and the development of techniques for its assessment, there is a consistent finding of a higher level of $\operatorname{IgE}$ in boys' than in girls' blood plasma [9, 10, 11, 12]. Most data obtained todate confirms also a higher level of $\mathrm{IgE}$ in umbilical blood of males $[4,8,12]$. Some papers, where a different clinical methodology has been implemented, present this correlation as a higher proportion of boys in the groups of children who have a higher total $\mathrm{IgE}$ level [13]. A similar method was adopted by the authors of the present paper, confirming an association of male gender with a higher total $\mathrm{IgE}$ level.

Factors associated with pregnancy and labor are seldom discussed in the literature with respect to their impact on the IgE level in umbilical blood plasma. In the present paper, we found that maternal respiratory tract infections in the 1 st and 2 nd trimester were associated with increased total $\mathrm{IgE}$ level in the neonates. Other complications of pregnancy, however, had no major effects. The latter is concordant with the current knowledge concerning this problem. In spite of isolated publications discussing these issues, general opinion is that body height, Apgar score, the number of past pregnancies, the number of miscarriages and parental age do not influence the $\operatorname{IgE}$ level or the course of the allergization process. Therefore, these factors cannot be helpful in the assessment of the risk of the development of atopic diseases in children [8, $13,14]$. Studies published hitherto do not reveal any association between the total $\operatorname{IgE}$ level and birth weight of the newborn $[8,12,14]$.

We did not find any correlations between parental socio-economic status, education or life-style and the $\mathrm{IgE}$ concentration in umbilical blood; the interpretation of the lack of correlation is, however, hindered by a fairly homogenous study group. A matter of much debate is the role of maternal and infant contact with domestic animals. Some allergists consider that prolonged contact with domestic animals is a form of natural specific immunotherapy, effective particularly at the infant age, reducing hypersensivity to animal fur $[15,16]$. This phenomenon may be a result of tolerance achieved during natural exposition to high concentration of allergens [17]. Other authors postulate that the presence of a pet may result in the development of allergy and exacerbation of its symptoms.
This relates particularly to cat allergens [18]. The issue of whether we should present a cat to a small child still remains unresolved. In the present study, maternal contact with a cat during pregnancy resulted in increased incidence of antigen-specific immunoglobulins E against grass, cereals, and foods. That may signal the role of cat allergens acting during pregnancy in the development of allergies. In contrast, maternal exposure to dog allergens during pregnancy was associated with decreased incidence of sIgE against grass and cereals; a trend also seen regarding antibodies against domestic dust mites. Gern et al. [19] also demonstrate less frequent hypersensivity and lower incidence of atopic dermatitis in infants remaining in a continuous contact with a dog since birth.

A widely discussed factor is active and passive tobacco smoking by pregnant women. Authors are highly discordant when assessing the influence of smoking on total $\mathrm{IgE}$. Some suggest that maternal exposure to either type of smoking has a significant impact on $\operatorname{IgE}$ levels in both maternal and fetal blood plasma and on the development of atopic diseases in early infancy (6, $7,8)$. Bergman et al. [13] showed a high IgE level in children of smoking fathers and even higher levels of it in children of smoking mothers. Surprisingly, the lowest $\operatorname{IgE}$ levels were noted in newborns where both parents smoked. This finding was explained by nonspecific stimulation of fetal IgE production when exposed to low-intensity passive smoking and blockade thereof when faced with heavy exposure to tobacco smoke. However, many authors emphasize that no significant correlation between total $\mathrm{IgE}$ level and smoking during pregnancy or maternal exposure to tobacco smoke has been found to-date $[14,20]$. In the present study we did not find any correlation between parental smoking and total IgE level either. Nevertheless, it is worth pointing out that maternal or parental smoking was associated with higher incidence of $\operatorname{sIgE}$ against domestic dust mites. We may presume that women living in an environment of tobacco smoke had greater contact with domestic dust mite allergens, and that may result in higher incidence of atopic diseases in the future.

In conclusion, in the present study we demonstrate that increased total $\mathrm{IgE}$ level in umbilical blood was associated with male gender, pathological pregnancy course, and the presence of atopic rhinitis in the family; while lower IgE levels were found in children having numerous siblings. Increased levels of specific IgE against grass, cereals, and food stuffs were associated with maternal contact with a cat, but not a dog, and with parental smoking during pregnancy.

Conflicts of interest: The authors reported no conflicts of interest in relation to this article.

\section{REFERENCES}

[1] Kaiser HB. Risk factors in allergy/asthma. Allergy Asthma Proc 2004; 25: 7-10.

[2] European Allergy White Paper Update. Epidemiology. Brussels: The UCB Institute of Allergy, 1999.

[3] Shah S, Bapat MM. Parental history of allergy, maternal serum IgE \& cord serum IgE. Indian J Med Sci 2006; 60: $13-8$. 
[4] Scirica CV, Gold DR, Ryan L, Abulkerim H, Celedón JC, Platts-Mills TA, Naccara LM, Weiss ST, Litonjua AA. Predictors of cord blood $\mathrm{IgE}$ levels in children at risk for asthma and atopy. J Allergy Clin Immunol 2007; 119: 818.

[5] Bertino E, Bisson C, Martano C, Coscia A, Fabris C, Monti G, Testa T, Conti A. . Relationship between maternaland fetal-specific IgE. Pediatr Allergy Immunol 2006; 17: 484-8.

[6] Furuhashi M, Sugiura K, Katsumata Y. Cord blood IgE against milk and egg antigens. Biol Neonate 1997; 72: 210-5.

[7] Bohme M, Wickman M, Lennart Nordvall S, Svartengren $\mathrm{M}$, Wahlgren CF. Family history and risk of atopic dermatitis in children up to 4 years. Clin Exp Allergy 2003; 33: 1226-31.

[8] Stabell Benn C, Wohlfahrt J, Aaby P. Breastfeeding and risk of atopic dermatitis, by parental history of allergy, during the first 18 months of life. Am J Epidemiol 2004; 160: 217-23.

[9] Halken S. Prevention of allergic disease in childhood: clinical and epidemiological aspects of primary and secondary allergy prevention. Pediatr Allergy Immunol 2004; 15 : 9-32.

[10] Rivas MA, Boné J, Rituerto B, Alonso JP, Franco Y, Guallar A, Baldellou A. Cord blood IgE versus family history as atopic predictors in the newborn. Acta Paediatr 1994; 83: 1308-9.

[11] Julge K, Vasar M, Bjorksten B. Development of allergy and $\mathrm{IgE}$ antibodies during the first five years of life in Estonian children. Clin Exp Allergy 2001; 31: 1854-61.

[12] Høst A, Halken S, Jacobsen HP, Christensen AE, Herskind AM, Plesner K. Clinical course of cow's milk protein allergy/intolerance and atopic diseases in childhood. Pediatr Allergy Immunol 2002; 13: 23-8.

[13] Bergmann RL, Schulz J, Gunther S, Dudenhausen JW, Bergmann KE, Bauer CP, Dorsch W, Schmidt E, Luck W, Lau $\mathrm{S}$ et al. Determinants of cord-blood $\mathrm{IgE}$ concentrations in 6401 German neonates. Allergy 1995; 50: 65-71.

[14] Siltanen M, Kajosaari M, Pohjavuori M, Savilahti E. Prematurity at birth reduces the long-term risk of atopy. J Allergy Clin Immunol 2001; 107: 229-34.
[15] Kaan A, Dimich-Ward H, Manfreda J, Becker A, Watson W, Ferguson A, Chan H, Chan-Yeung M. Cord blood IgE: its determinants and prediction of development of asthma and other allergic disorders at 12 months. Ann Allergy Asthma Immunol 2000; 84: 37-42.

[16] de Marco R, Pattaro C, Locatelli F, Svanes C. ECRHS Study Group. Influence of early life exposures on incidence and remission of asthma throughout life. J Allergy Clin Immunol 2004; 113: 845-52.

[17] Erwin EA, Wickens K, Custis NJ, Siebers R, Woodfolk J, Barry D, Crane J, Platts-Mills TA. Cat and dust mite sensitivity and tolerance in relation to wheezing among children raised with high exposure to both allergens. J Allergy Clin Immunol 2005; 115: 74-9.

[18] Lopez N, de Barros-Mazon S, Vilela MM. Are immunoglobulin $\mathrm{E}$ levels associated with early wheezing? A prospective study in Brazilian infants. Eur Respir J 2002; 20: 640-5.

[19] Gern JE, Reardon CL, Hoffjan S, Nicolae D, Li Z, Roberg KA, Neaville WA, Carlson-Dakes K, Adler K, Hamilton R, Anderson E, Gilbertson-White S, Tisler C, Dasilva D, Anklam K, Mikus LD, Rosenthal LA, Ober C, Gangnon R, Lemanske RF Jr. Effects of dog ownership and genotype on immune development and atopy in infancy. J Allergy Clin Immunol 2004; 113: 307-14.

[20] Hansen LG, Høst A, Halken S, Holmskov A, Husby S, Lassen LB, Storm K, Osterballe O. Cord blood IgE. I. IgE screening in 2814 newborn children. Allergy 1992; 47: 391-9.

Address for correspondence:

Adam J. Sybilski

Department of Pediatric and Neonatology

Central Clinical Hospital of Ministry of Internal Affairs

137 Woloska St.

02-507 Warsaw, Poland

Phone +48225081221

Fax +48225081220

E-mail: Adam.sybilski@cskmswia.pl 